\title{
Template Synthesis into Gelatin-Immobilized Matrix as Perspective Method of Obtaining Supramolecular Macroheterocyclic Compounds
}

\author{
Oleg V. Mikhailov, ${ }^{\mathrm{@}}$ Marina A. Kazymova, ${ }^{\mathrm{b}}$ and Denis V. Chachkov ${ }^{\mathrm{b}}$ \\ ${ }^{a}$ Kazan State Technological University, 420015 Kazan, Russia \\ ${ }^{b}$ Kazan State University, 420015 Kazan, Russia \\ ${ }^{\circledR}$ Corresponding authorE-mail: ovm@kstu.ru
}

\begin{abstract}
Template synthesis processes proceeding for $M^{I I}$ ion - ligand synthon I - ligand synthon II triple systems $(M=C o$, $\mathrm{Ni}, \mathrm{Cu}$ ) into solutions and gelatin-immobilized matrix, have been obtained and analyzed. It has been shown that final results of these processes are distinguished extremely considerably. The distinction predicted has been displayed by examples of template synthesis for some $M^{I I}-(N, S)$-, $(N, O, S)$-ambidentate ligand synthon - $(C=O)$-containing ligand synthon in water-ethanol solutions and metalhexacyanoferrate gelatin-immobilized matrix implantates. The quantumchemical calculation of structures of macrocyclic coordination compounds formed as a result of template processes, has been carried out with using DFT B3LYP method.
\end{abstract}

\section{Introduction}

Template synthesis is known to be one of extremely important synthetic methods of modern coordination and supramolecular chemistry. ${ }^{[1-4]}$ In this method, metal ion having specific stereochemistry of coordination environment and electronic structure, is a peculiar "pattern" and ensures a formation of such specific metallocomplexes, the synthesis of which under other conditions either has been very difficult or cannot be realized at all. In principle, template synthesis enables to obtain metallomacrocyclic and supramolecular coordination compounds, including even having very complex structure (for example, coordination compounds of various metal ions with phthalocyanines and porphirines) from comparatively simple starting chemical compounds (what are known as ligand synthons). However, such a synthetic method leads to formation of chemical compounds which are of far more complex composition and structure compared with starting ligand synthones, and, according to general rule of chemical thermodynamic, it proceeds with considerable decrease of entropy of reactionary medium. In conformity with classic equation for isobaric chemical process $\Delta G=\Delta H-T \Delta S$ ( $\Delta G, \Delta H$ and $\Delta S$ is change of Gibbs's energy, enthalpy and entropy in the course of chemical reaction, respectively, $T$ is a temperature in $\mathrm{K}$ ), the possibility of realization of any process accompanied with entropy decrease, decreases with temperature growth. In this connection, at relatively low temperatures, template processes owing to considerable values of activation energy have very small rates; at relatively large $T$ values, when the rate of given processes may be acceptable with practical point of view, these reactions are thermodynamically forbidden. In any way, such a state of things may be eased by force of high pressure to reactionary medium under relatively small temperature, and, what is more, during of extremely long time (up to several hours). ${ }^{[1,3]}$ That is why, "softening" of conditions of template synthesis, and, first of all, of ensuring of possibility of its realization in conditions what are known as standard $(T=298 \mathrm{~K}, p=101325 \mathrm{~Pa})$, is one of actual problems of modern synthetic coordination chemistry.

\section{Theoretical consideration}

One of possible ways to decision of given problem, preliminary "regulation" of reactionary system (and, namely, "compulsory" decrease of entropy in it) which, as it is easily noticed, leads to that tangent of angle of slope of linear $\Delta G(T)$ dependence to abscissa axe decreases, may be. Indeed, because entropy is additive value, and, in the case of availability of such a preliminary "regulation", general equation $\Delta S=\Delta S^{\prime}+\Delta S_{o s}$, where $\Delta S$ is a change of entropy of reaction in an absence of "regulation" indicated, $\Delta S$ ' is a change of of entropy of reaction in an availability of it, $\Delta S_{o s}$ is a change of entropy in the course of the very "regulation", will takes place. As a result, the equation of $\Delta G^{\prime}(T)$ dependence in the system where "compulsory" decrease of entropy indicated takes place, is described as

$$
\Delta G^{\prime}=\Delta H-T\left(\Delta S-\Delta S_{o s}\right)
$$

and, because $\Delta S_{o s}$ is negative value, $\Delta S<0$, hence, $\left|\Delta S-\Delta S_{o s}\right|<|\Delta S|$. According to this, the range of temperature values in which given template process is thermodynamically possible, increases. This circumstance is illustrated by Figure 1 .

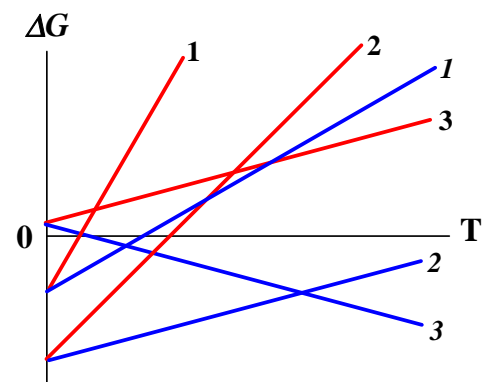

Figure 1. $\Delta G(T)$ dependences $(1,2,3)$ и $\Delta G^{\prime}(T)$ ones $(1,2,3)$ for three various variants of template process: 1,1 and 2,2 - for such template processes having $\Delta H<0$ which, in principle, can be realized in the metal ion - ligand synthon I - ligand synthon II triple systems without "compulsory" decrease of entropy indicated, 3, 3- for template process having $\Delta H>0$ which may be realized only in the case of "compulsory" decrease of entropy. Lower slope of straight lines of $\Delta G(T)$ and $\Delta G^{\prime}(T)$ dependences to abscissa axe has been clearly seen. 
One of examples of reactionary mediums where such preliminary "regulation" of reactionary system and "compulsory" decrease of entropy occurs, are biopolymerimmobilized matrix (for example, thin-layer implantate on some film) containing immobilized coordination compound. The most suitable biopolymer for creation of matrix indicated is gelatin which very easily forms thin transparent layers. A length of gelatin molecule is $\sim 285000$ pm whereas its diameter only $1400 \mathrm{pm}$; this molecule is sharply asymmetric. A typical fragment of structure of the given polymer is shown in the Figure 2.

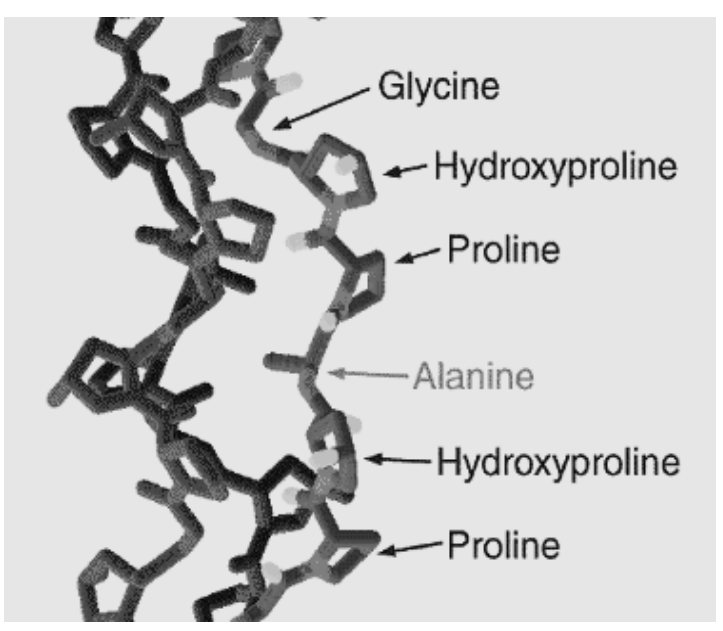

Figure 2. Three polypeptide $\alpha$-chains form a triple-helix of gelatin. Gelatin is stabilized by the formation of covalent crosslinks, both within the gelatin triple helix and between gelatin helices. ${ }^{[5]}$

Such a structure is potentially very suitable for the formation of polymer-immobilized matrix materials; it permits the formation of no kind of rigid crystalline blocks and furthermore, contains a fairly large number of cells for the reception and subsequent fixation of the molecules of the immobilized substance. When filled with the molecules of corresponding compound, these cells retain a certain freedom of migration in space. With a polymer of such a structure, it may be, in principle, to obtain immobilized matrix systems characterized by a fairly uniform distribution of the metal-containing chemical compounds in some part of the polymer massif. In addition, such immobilized matrices are sterically accessible for the occurence of diverse chemical processes in particular chemical processes and, among their number, template synthesis reactions. Gelatin has an extremely high surface area and an extensive system of micropores, so that when it comes into contact with any kind of aqueous solution, the permeation of both the solvent molecules and of the solute into polymer massif is a rule ensured comparatively readily. ${ }^{[5-8]}$ In this connection, polymer layers on the basis of gelatin exhibits isotropic physical and mechanical parameters and is transparent, hydrophilic, and plastic.

One of most suitable immobilized substances are hexacyanoferrates(II) of various transition metals having general formula $\mathrm{M}_{2}\left[\mathrm{Fe}(\mathrm{CN})_{6}\right]$ where $\mathrm{M}=\mathrm{VO}, \mathrm{Mn}, \mathrm{Co}, \mathrm{Ni}$, $\mathrm{Cu}, \mathrm{Zn}, \mathrm{Cd}$ et al. According to experimental data, such thinlayer gelatin-immobilized matrix implantates containing these coordination compounds (further MHF-GIM) are transparent as regards to electron flow, and, hence, have

nano-structured level of organization of immobilized substance. On the other hand, the overwhelming majority of template reaction found is known to be a variant of Shiff's condensation accompanied with intra-molecular formation of water at the expense of mobile hydrogen atoms of one ligand synthon and oxygen atoms of another ligand synthon. ${ }^{[3]}$ A probability of any such a template reaction is the higher, the more mobile hydrogen atoms in corresponding ligand synthon, that, in its turn, is connected with proton-donor ability of this chemical compound. Because gelatin molecules, as ampholyte and polyelectrolyte, acquire in alkaline medium the negative charge, proton-donor ability of any chemical compound immobilized in this polymer mass, becomes more considerable in comparison with proton-donor ability of this compound in water solution. Hence, template synthesis into MHF-GIM, in principle, must proceed more effectively than in solution or solid phase. It should be noted in this connection that as a result of template synthesis in MHFGIM, supramolecular metalheterocyclic coordination compounds in which template complex ("core") is connected with gelatin molecules by intermolecular forces, are formed.

It was noted in reviews ${ }^{[9,10]}$ that character of template synthesis into MHF-GIM for a number of systems (metal ion - ligand synthones) differs considerably from character for template synthesis in conditions what is known as «traditional» (that is to say in solution and solid phase). In this connection, the given paper is short review of basic results of template reactions in the $\mathrm{M}^{\mathrm{II}}-(\mathrm{N}, \mathrm{S})-,(\mathrm{N}, \mathrm{O}, \mathrm{S})$ ambidentate ligand synthon $-(\mathrm{C}=\mathrm{O})$-containing ligand synthon triple systems proceeding into MHF-GIM and collation of them with results of template reactions in the same systems in water-ethanol solutions.

\section{Results and Discussions}

As suitable objects to give possibility more clearly to reveal such distinctions, are ambidentate ligand synthones. They have in its composition three or more number of donor centers and capable to coordinate to metal ion by various way in dependence of conditions of realization of complexing process. As ambidentate ligand synthon I, such $(\mathrm{N}, \mathrm{S})$ - and (N,O,S)-donoratomic organic compounds as ethanedithioamide-1,2, thiocarbamoylmethaneamide, hydrazinomethanethiohydrazide, propandithioamide-1,3, capable to coordinate to metal ion through nitrogen, sulfur and oxygen atoms, may be used:<smiles>NC(=S)C(N)=S</smiles>

Ethanedithioamide-1,2<smiles>NNC(=S)NN</smiles>

Hydrazinomethanethiohydrazide

The possible variants of coordination of these compounds to metal ion are presented in the Table 1. 
Table 1. The variants of coordination of ethanedithioamide-1,2, thiocarbamoylmethaneamide, hydrazinomethane-thiohydrazide and propandithioamide-1,3 to metal ions.

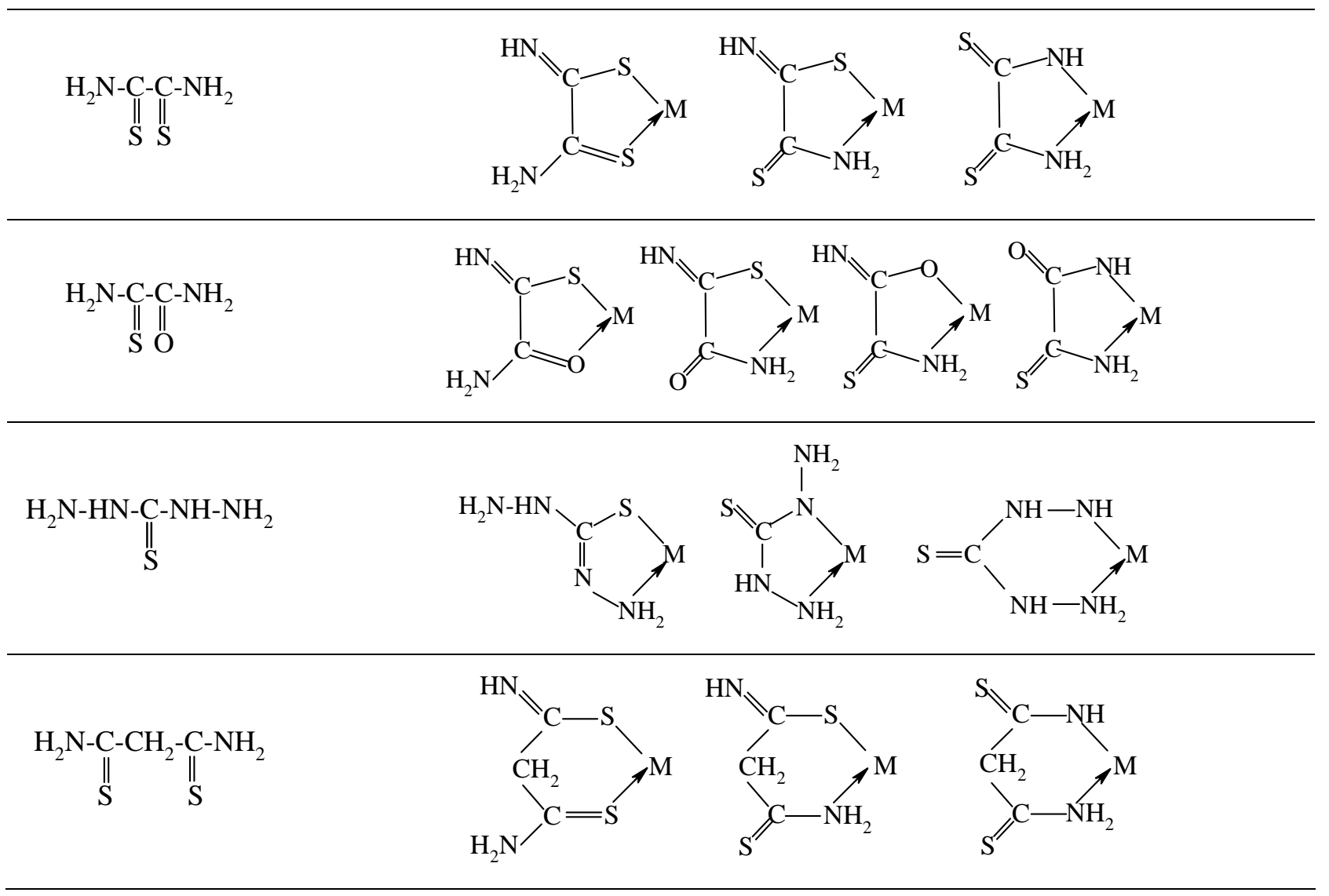

As ligand synthon II ensuring template "stitching" of metallochelate cycles in common closed contour, chemical compounds having carbonyl group $\mathrm{C}=\mathrm{O}$, for example methanal, ethanal, propanone, ethanedial, buthanedione-2,3 and penthanedione-2,4, may be used.

The data concerning the final products of template synthesis in triple systems containing some of ligand synthones indicated, is presented in the Table 2.<smiles>C=O</smiles>

Methanal<smiles>CC=O</smiles>

Ethanal<smiles>CC(C)=O</smiles>

Propanone<smiles>O=CC=O</smiles>

Ethanedial<smiles>CC(=O)C(C)=O</smiles>

Buthanedione-2,3<smiles>CC(=O)CC(C)=O</smiles>

Penthanedione- 2,4

Table 2. The products of complexing processes proceeding in the $\mathrm{M}^{\mathrm{II}}$ - (N,S)-containing ligand synthon - O-containing ligand synthon in the solutions or solid phase and in the $\mathrm{M}_{2}\left[\mathrm{Fe}(\mathrm{CN})_{6}\right]$-gelatin-immobilized matrix.

\begin{tabular}{|l|c|c|}
\hline \multirow{2}{*}{$\begin{array}{c}\text { Components of triple } \\
\text { system }\end{array}$} & Products of complexng processes \\
\hline 1 & 2 & In gelatin-immobilized matrix \\
\hline \multirow{2}{*}{$\begin{array}{l}\mathrm{M}^{\mathrm{II}} \\
\text { ethanedithioamide-1,2 } \\
\text { methanal } \\
(\mathrm{M}=\mathrm{Co})\end{array}$} & \multicolumn{2}{|c|}{} \\
\hline
\end{tabular}


Table 2 (continuation)

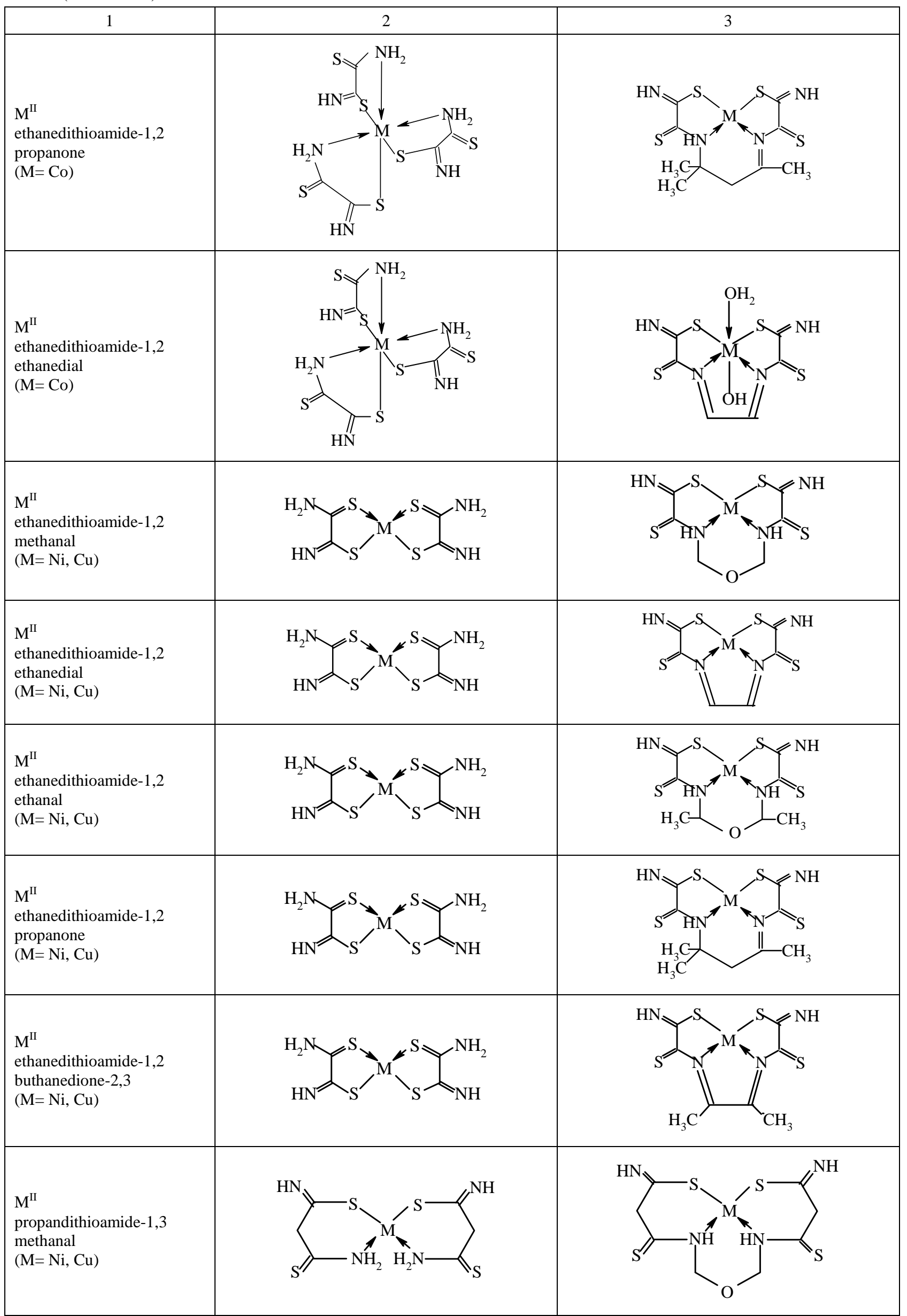


Table 2 (end)

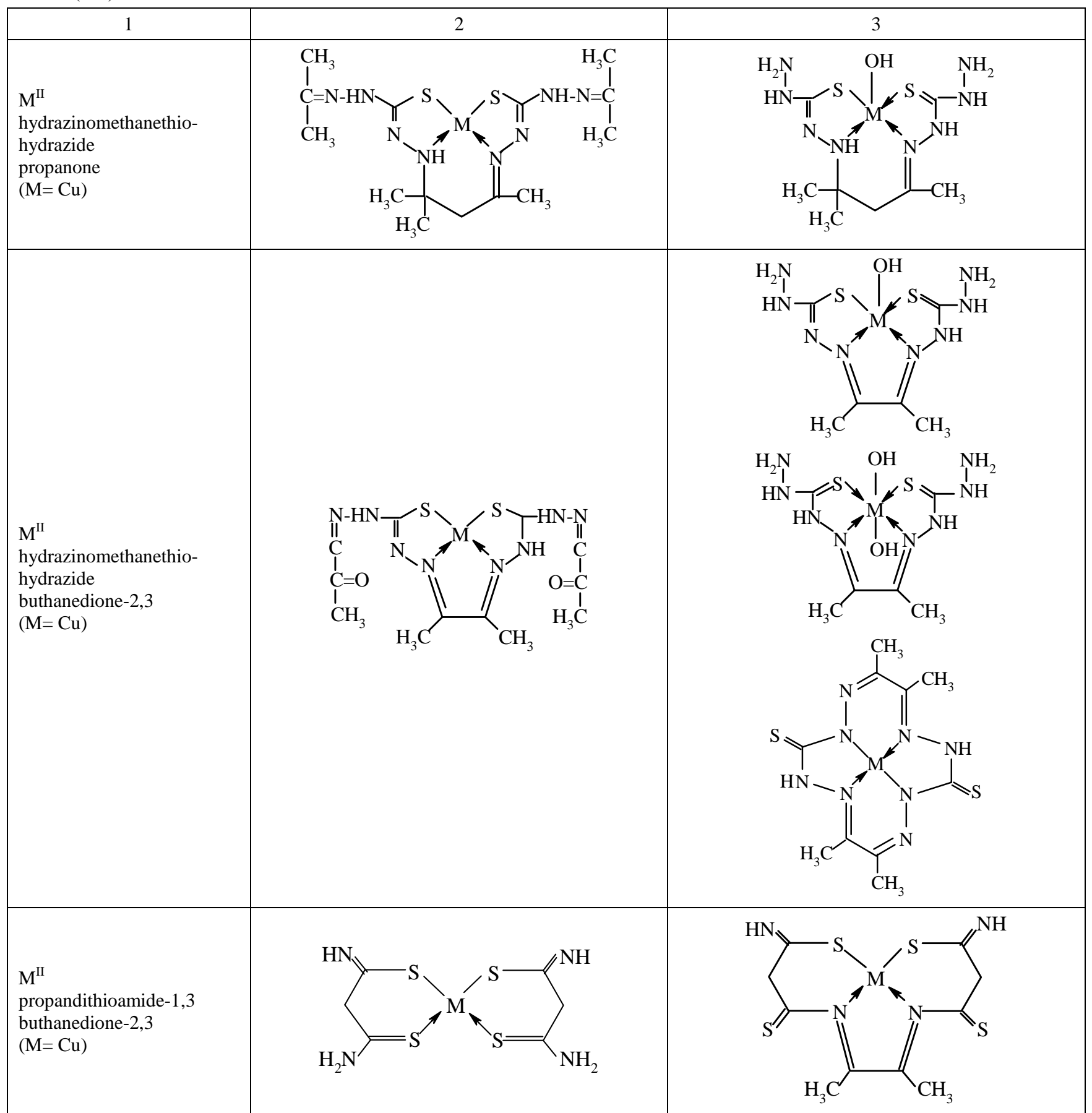

According to theoretical views indicated above, it may be expected that assortment of processes of template synthesis in a separately taken $\mathrm{M}^{\mathrm{II}}-(\mathrm{N}, \mathrm{S})$-containing ligand synthon - carbonyl-containing ligand synthon triple system in organizing reactionary medium with preliminary entropy decrease (and, among their number, into MHFGIM) will be more considerable than assortment of template processes in «traditional» conditions where the aforesaid decrease of $S$ values does not take place. It should be expected correspondingly to the above that a number of metalcomplexes formed as a result of realization of template processes in organizing medium must be more considerable than a number of metallocomlexes in «nonorganizing» one. The data presented in the Table 2 as it may be easily seen, are in full agreement with such a forecast, in the last resort, for triple systems containing $\mathrm{Cu}^{\text {II }}$ as a "template" metal ion; besides, in an availability in it of hydrazinomethanethiohydrazide, template synthesis in water-ethanol solution leads to formation of only one metallochelate whereas template synthesis into MHF-GIM, leads to two or even more their number; in an availability in it of ethanedithioamide-1,2 or propanedithioamide-1,3, template synthesis in water-ethanol solution does not occur (only bischelate copper(II) complexes with ligand synthons indicated) whereas template synthesis into MHF-GIM takes place. ${ }^{[1-15]}$

At the present time, quantum-chemical calculations of template complexes formed in the $\mathrm{M}^{\mathrm{II}}$ - ethanedithioamide-1,2 - methanal, $\mathrm{M}^{\mathrm{II}}$ - ethanedithioamide-1,2 - propanone and $\mathrm{M}^{\mathrm{II}}$ - hydrazinomethanethiohydrazide - propanone $(\mathrm{M}=\mathrm{Co}, \mathrm{Ni}$, $\mathrm{Cu}$ ) triple systems, were carried out by us. For this purpose, B3LYP 6-31G(d) method, which is hybrid DFT method using Becke function (1988) including Slater exchange, by beginning with amendment including density gradient, and correlation function of Lee, Yang and Parr, which includes 
local and non-local therms, ${ }^{[16]}$ was used by us for calculations. The energy values $E$ were calculated according to equation (2)

$$
E=V+\langle\mathrm{h} P\rangle+1 / 2\langle\mathrm{PJ}(P)\rangle+\mathrm{EX}[P]+\mathrm{EC}[P]
$$

where $V$ is nuclearic energy of repulsion, $\langle\mathrm{h} P\rangle-$ oneelectronic (kinetic + potential) energy, $1 / 2\langle\mathrm{PJ}(P)\rangle-$ energy of electrons repulsion, $\mathrm{EX}[P]-$ exchange function; $\mathrm{EC}[P]-$ correlation function. 6-31G(d) basic set where each inner atom orbital (AO) is described by six functions of Gauss type (GTO), valence $2 s$ AO- by three GTO, valence $p$-AO by one GTO, with addition of polarization $d$-GTO to each $p$-function, was used. All calculations were made with using Gaussian 98 program. ${ }^{[17]}$ Time of quantum-chemical calculations of complexes studied was from 3 to 15 months. According to experimental data presented in Table 2, $(\mathrm{N}, \mathrm{N}, \mathrm{S}, \mathrm{S})$-coordination of donor centers of chelate ligand to $\mathrm{M}^{\mathrm{II}}$ occurs in the complexes arising as a result of template synthesis in the systems indicated. Such coordination does not contradict a conception of "hard" and "soft" Pearson's acids and bases. ${ }^{[18]}$ Among their number, for $\mathrm{M}^{\mathrm{II}}-$ ethanedithioamide-1,2 - propanone systems, template process is described with general equation (3):
A numbering of atoms in these complexes is shown in the Figure 3; the space structures of given template complexes obtained as a result of quantum-chemical calculations, are presented in the Figures 4-6. As may be seen from the data presented, coplanar coordination of donor centers of ligand related metal ion is more preferable for $\mathrm{Ni}^{\mathrm{II}}$ and $\mathrm{Cu}^{\mathrm{II}}$ complexes under examination, with $M_{S}$ of basic state equal to 1 and 2, respectively. This circumstance is in a full harmony with experimental data published in $^{[19,20]}$ according to which, planar structure seems most probable for given $\mathrm{Ni}^{\mathrm{II}}$ and $\mathrm{Cu}^{\mathrm{II}}$ complexes. For $\mathrm{Co}^{\mathrm{II}}$ complex, however, is more preferable quasi-tetrahedral coordination with $M_{S}=4$. The distinctions between energies of structures having $M_{S}$ value differ from $M_{S}$ of basic state [doublet in the case of $\mathrm{Co}^{\mathrm{II}}$, triplet in the case of $\mathrm{Ni}^{\mathrm{II}}$ and quartet in the case of $\mathrm{Cu}^{\mathrm{II}}$ are $10.2,25.6$ and 65.7 $\mathrm{kJ} /$ mole, respectively]. The average $\mathrm{M}-\mathrm{N}$ and $\mathrm{M}-\mathrm{S}$ bond lengths in planar $\mathrm{Ni}^{\mathrm{II}}$ and $\mathrm{Cu}^{\mathrm{II}}$ complexes are 187.7 and $219.9 \mathrm{pm}$ in the case of $\mathrm{Ni}^{\mathrm{II}}, 203.0$ and $227.5 \mathrm{pm}$ in the case of $\mathrm{Cu}^{\text {II }}$. In the $\mathrm{Co}^{\mathrm{II}}$ complex having quasi-tetrahedral coordination, these bonds are longer than in planar complexes indicated (214.9 and $228.0 \mathrm{pm}$, respectively).

$$
2
$$

As can be seen they are extremely appreciably distinguished.

The additional six-numbered cycle containing N-C$\mathrm{CH}_{2}-\mathrm{C}-\mathrm{N}$ grouping formed as a result of template "stitching", is not in one flatness with $\mathrm{N}_{2} \mathrm{~S}_{2}$ donor centers; it has been rather considerably inclined to flatness indicated even in the case of $\mathrm{Ni}^{\mathrm{II}}$ and $\mathrm{Cu}^{\mathrm{II}}$ complexes having planar structure. It should be noted in this connection that in the case of $\mathrm{Ni}^{\mathrm{II}}$ complex, the angle between $\mathrm{Co}(13), \mathrm{N}(5)$ and $\mathrm{C}(18)$ atoms is $107^{\circ} .6$, between $\mathrm{Co}(13), \mathrm{N}(5)$ and $\mathrm{C}(17)$, is $126^{\circ} .2$; dihedral angle between $\mathrm{C}(2), \mathrm{C}(3), \mathrm{N}(5)$ and $\mathrm{C}(18)$ is $130^{\circ}$.6, between $\mathrm{C}(2), \mathrm{C}(3), \mathrm{N}(5)$ and $\mathrm{C}(17)$ is $69^{\circ} .0$. The analogous angles in the case of $\mathrm{Cu}^{\text {II }}$ complex are $105^{\circ} .2,126^{\circ} .6,121^{\circ} .0$ and $73^{\circ} .5$, respectively. As may be seen from these data, the given additional cycle itself is extremely distorted - there are no set even of four atoms arranged in the same flatness, in it.
Figure 3. Atoms numbering in the structures of template complexes formed as a result of template synthesis according to reaction (3).

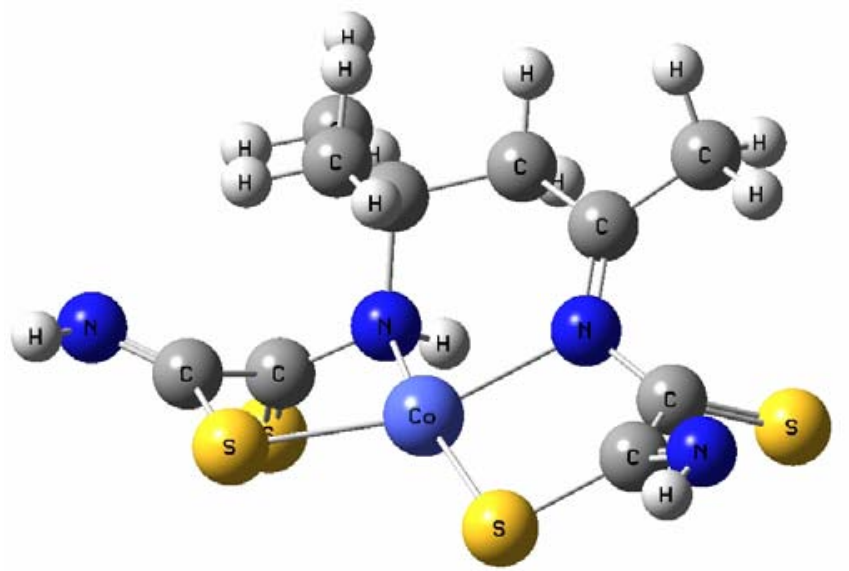

$\boldsymbol{A}$

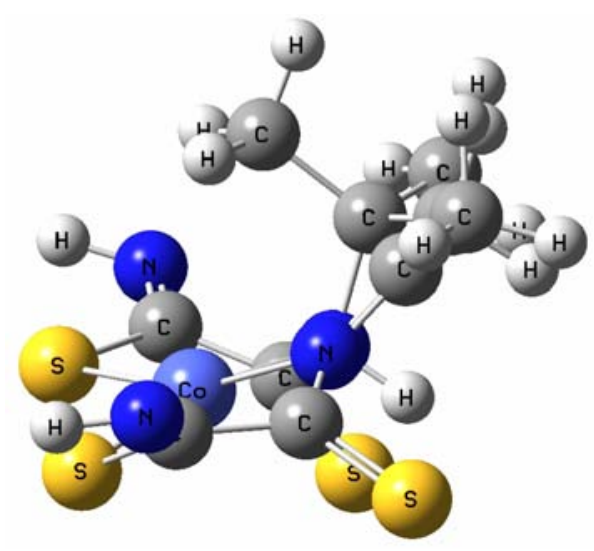

$\boldsymbol{B}$

Figure 4. The space structure of cobalt(II) complex with (N,N,S,S)-coordination of donor centers of "template" ligand to $\mathrm{M}^{\mathrm{II}}$ formed in the Co II - ethanedithioamide-1,2 - propanone triple system: "open", front view $(A)$ and "shielded", view from the side $(B)$. 


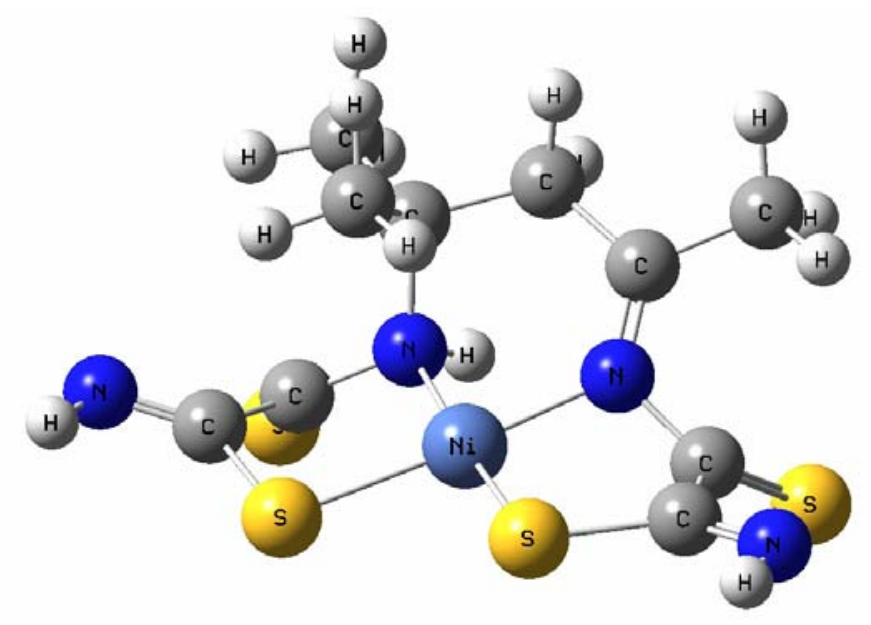

$\boldsymbol{A}$

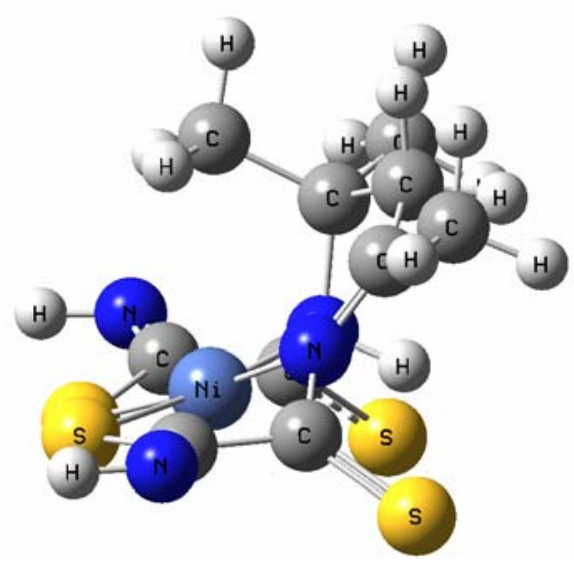

$\boldsymbol{B}$

Figure 5. The space structure of nickel(II) complex with (N,N,S,S)-coordination of donor centers of "template" ligand to $\mathrm{M}^{\mathrm{II}}$ formed in the $\mathrm{Ni}^{\mathrm{II}}$ - ethanedithioamide-1,2 - propanone triple system: "open", front view $(A)$ and "shielded", view from the side $(B)$.

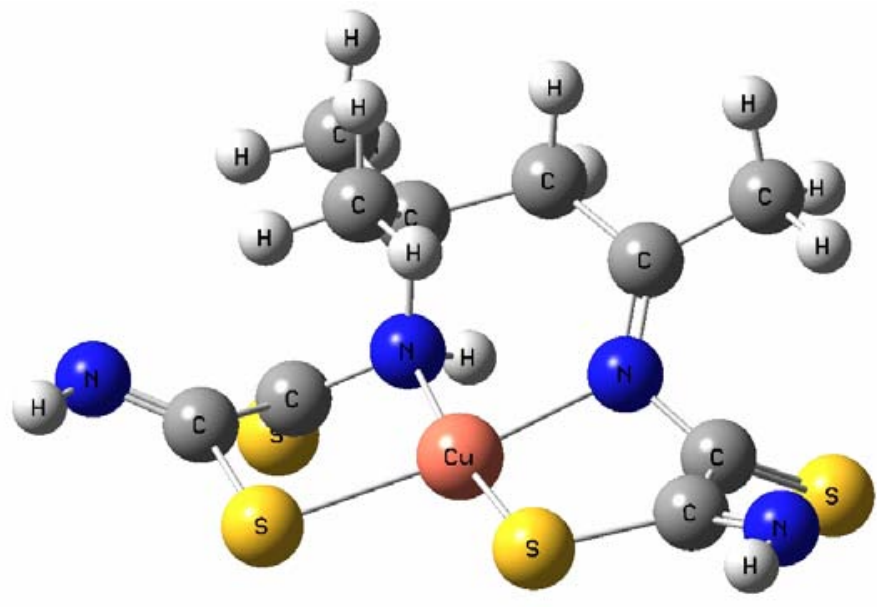

$\boldsymbol{A}$

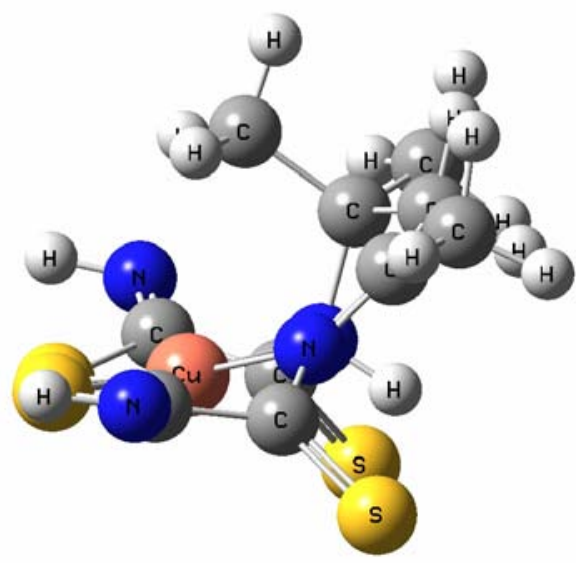

$\boldsymbol{B}$

Figure 6. The space structure of copper(II) complex with (N,N,S,S)-coordination of donor centers of "template" ligand to $\mathrm{M}^{\mathrm{II}}$ formed in the $\mathrm{Cu}^{\mathrm{II}}$ - ethanedithioamide-1,2 - propanone triple system: "open", front view $(A)$ and "shielded", view from the side $(B)$.

It should be noted in this connection that according to data of given quantum-chemical calculations of other macrocyclic complexes containing plane $\mathrm{N}_{2} \mathrm{~S}_{2}$ chelate grouping and six-numbered additional cycles, the sixnumbered cycles indicated are extremely sharply inclined to flatness of $\mathrm{N}_{2} \mathrm{~S}_{2}$ chelate groupings, too.

\section{Conclusions}

As can be seen from foregoing, template synthesis in the MHF-GIM is specific phenomenon in coordination chemistry of transition metals. It should be noted especially that at the template synthesis under such unusual conditions which take place in gelatin-immobilized matrix systems, supramolecular coordination compounds which were not been obtained up to now at template synthesis either in solution or solid phase, can be formed. Most sharply this distinction is in that case when if only one of participants of template reaction is ambidentate ligand synthon, for example, some of $(\mathrm{N}, \mathrm{S})$-ligand synthons considered in this article. Besides, as a rule, at the template synthesis in the MHF-GIM there is formed more considerable number of coordination compounds that at complexing under "traditional" conditions. Undoubtedly, template synthesis in the MHF-GIM merits of close attention of chemists working in this specific field of chemical science. That is why, new researches need in given field to understand the nature of this phenomenon, to forecast of compositions of metalcomplexes formed and to learn to guide with it.

Acknowledgements. The Russian Foundation of Basic Researches (RFBR) is acknowledged for financial support of given work (grant No. 06-03-32003). Also, authors are grateful Supercomputer Center of Kazan Scientific Center of Russian Academy of Sciences where all quantumchemical calculations were carried out.

\section{References}

1. Gerbeleu N.V., Arion V.B. Template Synthesis of Macrocyclic Compounds. Kishineu, Stiinta, 1990, 374. (in Russ.)

2. Lehn J.-M. Supramolecular Chemistry: Conceptions and Perspectives. Novosibirsk, Siberian Section of Russian Academy of Sciences, 1998, 334. (in Russ.) 
3. Gerbeleu N.V., Arion V.B., Burgess J. Template Synthesis of Macrocyclic Compounds. Weinheim, New York - ChichesterBrisbane - Singapore - Toronto, Wiley-VCH, 1999, 565.

4. Garnovskii A.D., Vasil'chenko V.S., Garnovskii D.A. Modern Aspects of Synthesis of Metalcomplexes. The Basic Ligands and Methods. Rostov, LaPO Publisher, 2000, 355. (in Russ.)

5. Chen J.M., Kung C.E.,, Feairheller S.E., Brown E.M. J. Protein Chem. 1991, 10, 535-540.

6. Fridman R, Fuerst T.R., Bird R.E., Hoyhtya M., Oelkuct M., Kraus S., Komarck D., Liotta L.A., M.L. Berman M.L., Stetler-Stevenson R. J. Biol. Chem. 1992, 267, 15398-15402.

7. Bányai L., Tordai H., Patthy L. J. Biol. Chem., 1996, 271, 12003-12007.

8. Tordai H., Patthy L. Eur. J. Biochem., 1999, 259, 513-518.

9. Mikhailov O.V. Russ. Chem. Bull. 1995, 64, 657-671.

10. Mikhailov O.V. Revs. Inorg. Chem. 1997, 18, 287-332.

11. Mikhailov O.V. Gelatin-Immobilized Metallocomplexes. Moscow, Scientific World, 2004, 236. (in Russ.)

12. Mikhailov O.V., M.A. Kazymova M.A., Shumilova T.A., Solovieva S.E. Transition Met. Chem. 2004, 29, 732-736.

13. Mikhailov O.V., Kazymova M.A., Chmutova G.A., Shumilova T.A., Solovieva S.E. Transition Met. Chem. 2005, 30, 18-21.
14. Mikhailov O.V., Kazymova M.A., Chmutova G.A., Shumilova T.A., Solovieva S.E. Transition Met. Chem. 2005, 30, 299-304.

15. Mikhailov O.V. J. Coord. Chem. 2008, 61, 1333-1384.

16. Becke A.D. J. Chem. Phys. 1993, 98, 1372-1378.

17. Frisch M.J., Trucks G.W., Schlegel H.B., Scuseria G.E., Robb M.A., Cheeseman J.R., Zakrzewski V.G., Montgomery J.A., Stratmann Jr. R.E., Burant J.C., Dapprich S., Millam J.M., Daniels A.D., Kudin K.N., Strain M.C., Farkas O., Tomasi J., Barone V., Cossi M., Cammi R., Mennucci B., Pomelli C., Adamo C., Clifford S., Ochterski J., Petersson G.A., Ayala P.Y., Cui Q., Morokuma K., Malick D.K., Rabuck A.D., Raghavachari K., Foresman J.B., Cioslowski J., Ortiz J.V., Baboul A.G., Stefanov B.B., Liu G., Liashenko A., Piskorz P., Komaromi I., Gomperts R., Martin R.L., Fox D.J., Keith T., Al-Laham M.A., Peng M.A., Nanayakkara A., Gonzalez C., Challacombe C., Gill P.M.W., Johnson B., Chen W., Wong M.W., Andres J.L., Gonzalez C., Head-Gordon M., Replogle E.S., Pople J.A. Gaussian 98. Gaussian Inc., Pittsburgh, 1998.

18. Pearson R.J. J. Amer. Chem. Soc. 1963, 85, 3533-3540.

19. Mikhailov O.V. Transition Met. Chem. 2000, 25, 552-558.

20. Mikhailov O.V. Int. J. Inorg. Mater. 2001, 3, 1053-1061. 